\title{
Comparative crystal structure determination of griseofulvin: Powder X-ray diffraction versus single-crystal X-ray diffraction
}

\author{
PAN QingQing, GUO Ping, DUAN Jiong, CHENG Qiang \& LI Hui* \\ College of Chemical Engineering, Sichuan University, Chengdu 610065, China
}

Received February 15, 2012; accepted March 31, 2012; published online June 29, 2012

\begin{abstract}
In an attempt to compare crystal structure determination from powder data and single-crystal data, crystal structure of griseofulvin $\left(\mathrm{C}_{17} \mathrm{H}_{17} \mathrm{ClO}_{6}\right)$ was tested by both powder and single-crystal X-ray diffraction. Lattice parameters of griseofulvin are $\alpha=90.0^{\circ}$, $a=b=8.9757 \AA, c=19.9345 \AA, V=1605.99 \AA^{3}$ from powder data coinciding with $\alpha=90.0^{\circ}, a=b=8.9714 \AA, c=19.8848 \AA, V=1600.46$ $\AA^{3}$ from single-crystal data. Main processes of structure elucidating of griseofulvin by the two approaches were analyzed. Powder X-ray diffraction was demonstrated to be a powerful auxiliary implement to single-crystal X-ray diffraction in structure characterization, and its application can be popularized in the field of structure research of small organic molecules.
\end{abstract}

griseofulvin, crystal structure, powder X-ray diffraction, single-crystal X-ray diffraction

Citation: Pan Q Q, Guo P, Duan J, et al. Comparative crystal structure determination of griseofulvin: Powder X-ray diffraction versus single-crystal X-ray diffraction. Chin Sci Bull, 2012, 57: 3867-3871, doi: 10.1007/s11434-012-5245-5

Powder and single-crystal X-ray diffraction are the two main methods in the field researching crystal structures of materials. Single-crystal X-ray diffraction is regarded to be the most powerful technique for elucidating crystal structures [1]. For structures with less than 100 atoms in the asymmetric unit, single-crystal techniques are always guaranteed to be successful with accurate parameters of cell dimensions [2]. However, many materials cannot be prepared in the form of single-crystal of sufficient size or stability for investigation using single-crystal X-ray diffraction techniques. Even if the single-crystal can be obtained, culturing single-crystal can be very time consuming. Therefore, applying powder X-ray diffraction techniques becomes essential to studying the structural properties of certain materials. Although structure determination by powder X-ray diffraction may not be as accurate as that by single-crystal X-ray diffraction, improvements will likely be achieved through future advancements in instrumentation and algorithm development [2]. Harris et al. [3], Evans et al. [4] and Tremayne [5] are crystal researchers who have provided

*Corresponding author (email: lihuilab@sina.com) important insight into the importance of powder X-ray diffraction for many years and have propelled its application.

Crystal structure of Jatrorrhizine chloride has been determined using both powder X-ray diffraction data and single-crystal X-ray diffraction data by Lei et al. [6] in 2009. The results from the two methods correlate with each other very well. To further investigate the comparison between powder and single-crystal X-ray diffraction we chose griseofulvin [7], crystal structure of which was determined by Puttaraja et al. [8] and Malmros et al. [9] from single-crystal diffraction data, as the researching material. Because regular griseofulvin crystals can be easily obtained in conventional circumstance for single-crystal X-ray diffraction and it has a rigid molecular structure (Figure 1) which can contribute to successful structure determination by powder $\mathrm{X}$-ray diffraction. The fact that results by the two techniques are identical demonstrates that powder X-ray diffraction can be as accurate as single-crystal X-ray diffraction in order to determine the crystal structure of griseofulivin. In addition, investigators in our laboratory have successfully determined the crystal structure of 7-amino-3-desacetoxy cephalosporanic acid [10] and $\beta$-cyclodextrin- $p$-aminobenzoic acid 
<smiles>COC1=CC(O)CC(C)C12Oc1c(Cl)c(OC)cc(OC)c1C2=O</smiles>

Figure 1 Molecular structure of griseofulvin.

inclusion complex [11] from powder X-ray diffraction data. Therefore we can further verify the accuracy of powder $\mathrm{X}$-ray diffraction to determine the crystal structure of small organic molecules.

\section{Experimental}

(i) Crystallization. Griseofulvin, with the purity of more than 99\%, was purchased from Zhuhai Yuancheng Pharmacetical \& Chemical Co., Ltd, China. The saturated solution of dimethy sulfoxide with griseofulvin was prepared at $70^{\circ} \mathrm{C}$, and colorless block-like crystals of griseofulvin were obtained after the solution being cooled to $25^{\circ} \mathrm{C}$. Regular crystals were selected for the single-crystal X-ray diffraction, and the others were grinded into powders for the powder X-ray diffraction.

(ii) Powder X-ray diffraction. Powder X-ray diffraction data were collected on X'Pert Pro MPD diffractometer (PANalytical) using $\mathrm{Cu} \mathrm{K} \alpha$ radiation $\left(\lambda_{1}=0.154056 \mathrm{~nm}\right)$ with $X^{\prime}$ celerator detector. The diffraciton data were recorded at $293 \mathrm{~K}$ with a stepsize of $0.01313^{\circ}$ and a counting time $10.16 \mathrm{~ms}$ per step in the $2 \theta$ range of $5^{\circ}-50^{\circ}$. The crystal structure determination of griseofulvin directly from powder diffraction data was conducted with Material Studio 4.2 (Accelrys Co., Ltd. USA) and direct space approach was chosen to solve the crystal structure then Rietveld method [12] was used to refine the crystal structure of griseofulivn.

(iii) Single-crystal X-ray diffraction. Single-crystal $\mathrm{X}$-ray diffraction data were collected on Oxford Diffraction Xcalibur Nova with Mo K $\alpha$ radiation $\left(\lambda_{1}=0.071073 \mathrm{~nm}\right)$ at $293 \mathrm{~K}$ and the $\theta$ range of $3.05^{\circ}-28.77^{\circ}$. Then single-crystal structure of griseofulvin was determined by program Olex2-1.1 [13] which can call the program SHELX, while the structure was solved by direct approach, and refined with the SHELX-97 program.

\section{Results and discussion}

\subsection{Indexing}

For single-crystal diffraction, the diffraction intensities are distributed in three-dimensional space, and the indexing is conducted by searching orientation matrix. In the process of collecting single-crystal diffraction data indexing results were obtained with a tetragonal cell, P41 space group and lattice parameters $\alpha=90.0^{\circ}, a=b=8.9714 \AA, c=19.8848 \AA$, $V=1600.46 \AA^{3}$. But the diffraction intensities are distributed in one dimensional space for the powder diffraction data, so peaks overlap in the powder diffraction pattern always makes the information on the individual diffraction intensity obscured. As a consequence, indexing is always deemed to be the bottleneck for crystal structure determination from powder X-ray diffraction data. In this work, in order to successfully index the powder diffraction pattern, the pattern was pretreated by calculating and subtracting the background then smoothing before stripping $\mathrm{K \alpha}_{2}$ radiation. Diffraction peaks were searched automatically based on the Savitsky-Golay method. Indexing was carried out using peak positions read from the powder diffraction profiles by $\mathrm{X}$-CELL method [14] then the indexing result was refined with the type of Pawley. This returned a tetragonal cell and P41 space group with lattice parameters $\alpha=90.0^{\circ}$, $a=b=8.9757 \AA, c=19.9345 \AA, V=1605.99 \AA^{3}$. Single-crystal $\mathrm{X}$-ray diffraction data are collected in three-dimensional space, but the data comes from one crystal, so the data may be contingent. Though powder X-ray diffraction data are collected from the compressing one dimensional space, they are statistics of numerous crystals. Therefore, the comparative indexing accuracy of the two diffraction methods requires an additional characterization step.

\subsection{Structure solution}

Direct space approach was chosen when structure solution of powder X-ray diffraction was executed. In direct space approach for solving crystal structure from powder diffraction data, appropriate trial structures were important for the subsequent work. For griseofulvin, all chemical bonds are covalent, so the bond length as well as the bond angle of each kind of these covalent bonds range more slightly than that of ionic bonds, consequently an approximately reasonable molecular structure of griseofulvin can be built and optimized by software based on quantum mechanics, molecular mechanics and so on. On the other hand, for the organic molecules, IR, MS, NMR and other methods can also provide structural information which can be utilized to build the trial structures. Herein, the structure of griseofulvin was created by Visual module in Materials Studio 4.2. The geometry of the structure was then optimized by minimizing its energy based on molecular mechanics simulation, and the final total potential energy was $-12.204 \mathrm{kcal} \mathrm{mol}^{-1}$ while the optimized structure and atomic labels of griseofulvin are shown in Figure 2. MC/SA search algorithm in Powder Solve package was used to constantly adjust the conformation, position and orientation of the trial model in the unit cell of griseofulvin determined from the indexing step in order to maximize the agreement between the calculated and the measured diffraction data. 


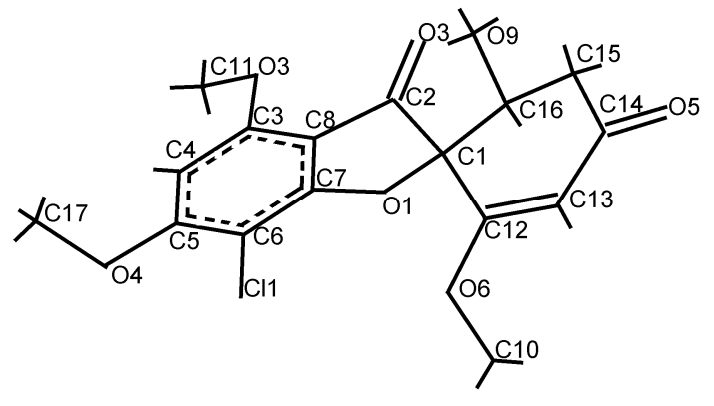

Figure 2 Optimized structure and atomic labels of griseofulvin.

As to single-crystal structure solution, direct method implemented in the SHELXS [15] program was applied to determine the positions of all atoms in the unit cell on the working platform Olex2-1.1. In the direct approach for solving crystal structure, phase information of various reflections was obtained from the kinds of diffraction intensities by using mathematical method. Then the electron density distribution in the unit cell can be further obtained from the phase information. Different electron density peaks correspond to different atoms, so each atom of griseofulvin was identified according to the electron density and the knowledge of structural chemistry, and the molecular structure of griseofulvin from single-crystal X-ray diffraction data is shown in Figure 3.

The identification of atomic types is always thought to be the obstacle in single-crystal X-ray diffraction especially structure of molecules with vast amount of atoms need to be solved, because the electronic density of carbon, nitrogen and oxygen are so similar that it is too difficult to distinguish them from each other independently. Fortunately, as mentioned above, IR, MS, NMR and other spectroscopy methods can be used as auxiliary implements to determine atom types of organic materials in this step.

\subsection{Refinement}

In order to obtain a satisfactory Rietveld refinement result from powder diffraction data, the initial structural model obtained from the structure solution step must be a sufficient representation of the correct structure as Rietveld

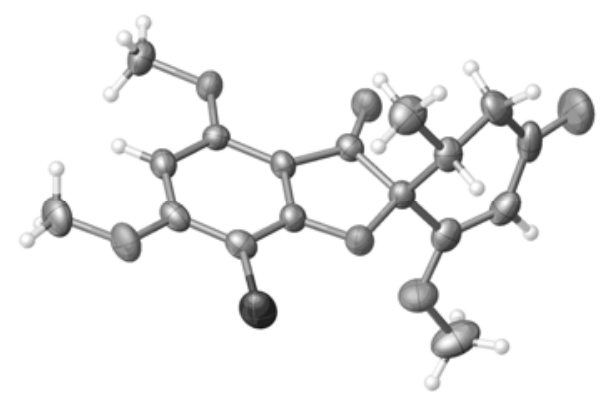

Figure 3 Molecular structure of griseofulvin from single-crystal X-ray diffraction. refinement often suffers from problems of instability. In this research, the physically reasonable crystal structure of griseofulvin obtained from MC/SA search was subsequently refined by Rietveld refinement techniques based on the measured powder X-ray diffraction pattern. In the Rietveld refinement, variables defining the structural model and the powder diffraction profile were adjusted by least squares methods in order to obtain an optimal fit between the experimental and calculated powder diffraction patterns. The final $R \mathrm{wp}$ of the structure was converged at $5.99 \%$, and the comparison between the measured X-ray diffraction pattern and the calculated pattern is shown in Figure 4.

However, for structure refinement from single-crystal $\mathrm{X}$-ray diffraction data, the structural model can sometimes be an incomplete representation of the true structure, because difference Fourier techniques can be adopted in conjunction with Rietveld refinement to complete the structural model. Herein, as the molecular structure of griseofulvin is known, all the atoms were easily identified from the electron density map, and the crystal structure was refined using full-matrix least-squares based on $F^{2}$ with the program SHELXL [16], and the refinement converged at $R_{1}=4.64 \%$.

The lattice parameters of griseofulvin from single-crystal $\mathrm{X}$-ray diffraction and powder X-ray diffraction are summarized in Table 1(data 4 and powder X-ray diffraction), and according to the research of Wei et al. [17] main functional bonds length and angles were summerized in Table 2. Final crystal structure of griseofulvin from the two technologies are shown in Figure 5, with single-crystal $R$ indices of $R_{1}=4.64 \%, \mathrm{w} R_{2}=8.65 \%$ and powder $R$ indices of $R \mathrm{p}=4.49 \%$, $R \mathrm{wp}=5.99 \%$. According to analysis in Table 1, deviations of powder X-ray diffraction from average of single-crystal $\mathrm{X}$-ray diffraction are relatively insignificant, thereby demonstrating the consistency of lattice parameters utilizing the two diffraction techniques. Table 2 shows the structural deviation of griseofulvin, and the modulus of deviation range from $0.09 \%$ to $4.21 \%$. The slight difference of molecular structure may be attributed to obscured diffraction intensities which result from three-dimensional single-

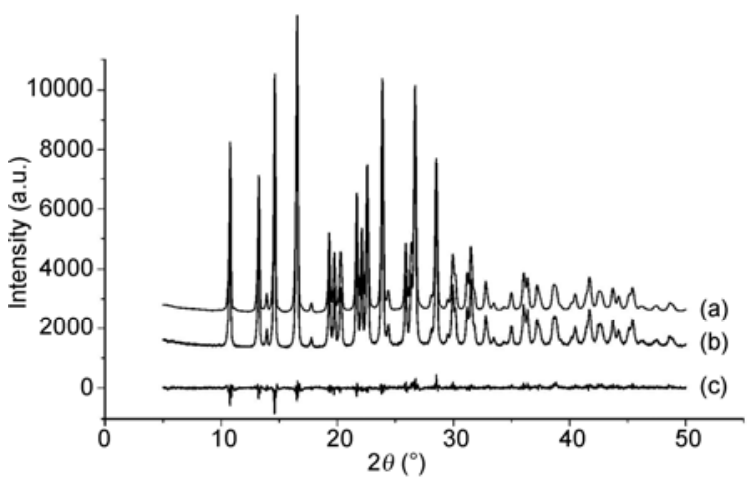

Figure 4 Comparison of powder X-ray diffraction pattern. (a) Calculated pattern; (b) measured pattern; (c) difference between measured pattern and calculated pattern. 


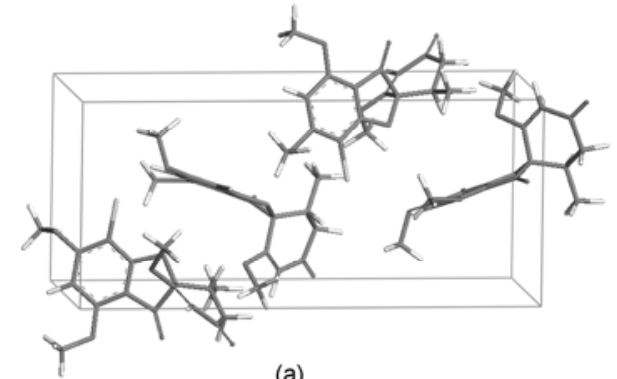

(a)

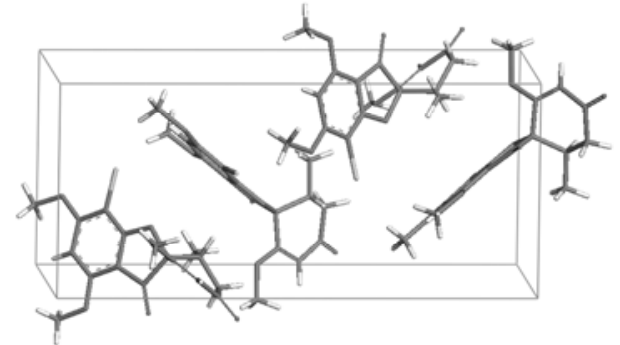

(b)

Figure 5 Crystal structure of griseofulvin by powder X-ray diffraction (a) and single-crystal X-ray diffraction (b).

Table 1 Lattice parameters ${ }^{\text {a) }}$

\begin{tabular}{|c|c|c|c|c|c|c|c|}
\hline \multirow{2}{*}{ List } & \multicolumn{5}{|c|}{ Single-crystal X-ray diffraction } & \multirow{2}{*}{ Powder X-ray diffraction } & \multirow{2}{*}{ Deviation (\%) } \\
\hline & Data 1 & Data 2 & Data 3 & Data 4 & Average & & \\
\hline$\alpha\left(^{\circ}\right)$ & 90 & 90 & 90 & 90 & 90 & 90 & 0 \\
\hline$a(\AA ̊)$ & 8.962 & 8.967 & 8.969 & 8.971 & 8.967 & 8.976 & 0.10 \\
\hline$c(\AA)$ & 19.895 & 19.904 & 19.951 & 19.885 & 19.909 & 19.935 & 0.13 \\
\hline$V\left(\AA^{3}\right)$ & 1597.92 & 1600.23 & 1604.92 & 1600.46 & 1600.88 & 1605.99 & 0.32 \\
\hline$Z$ & 4 & 4 & 4 & 4 & 4 & 4 & 0 \\
\hline
\end{tabular}

a) Data 1, 2 and 3 are from GRISFL, GRISFL02 and GRISFL03 respectively in Cambridge Crystallographic Data Cenetre.

Table 2 Bond length and angles for griseofulvin based on both powder X-ray diffraction and single-crystal X-ray diffraction

\begin{tabular}{|c|c|c|c|c|c|c|c|c|}
\hline & \multirow{2}{*}{ List } & \multicolumn{5}{|c|}{ Single-crystal X-ray diffraction } & \multirow{2}{*}{$\begin{array}{c}\text { Powder X-ray } \\
\text { diffraction }\end{array}$} & \multirow{2}{*}{ Deviation $(\%)$} \\
\hline & & Data 1 & Data 2 & Data 3 & Data 4 & Average & & \\
\hline \multirow{10}{*}{$\begin{array}{l}\text { Bond } \\
\text { length } \\
(\AA)\end{array}$} & $\mathrm{C} 1-\mathrm{C} 2$ & 1.5555 & 1.5643 & 1.5663 & 1.5600 & 1.5615 & 1.5393 & -1.42 \\
\hline & $\mathrm{C} 2-\mathrm{C} 8$ & 1.4479 & 1.4471 & 1.4388 & 1.4468 & 1.4452 & 1.4519 & 0.46 \\
\hline & $\mathrm{C} 7-\mathrm{O} 1$ & 1.3620 & 1.3632 & 1.3626 & 1.3631 & 1.3627 & 1.3966 & 2.49 \\
\hline & $\mathrm{C} 1-\mathrm{O} 1$ & 1.4509 & 1.4486 & 1.4419 & 1.4493 & 1.4477 & 1.4508 & 0.21 \\
\hline & $\mathrm{C} 1-\mathrm{C} 12$ & 1.5099 & 1.5124 & 1.5101 & 1.5115 & 1.5110 & 1.5393 & 1.87 \\
\hline & $\mathrm{C} 12-\mathrm{C} 13$ & 1.3379 & 1.3369 & 1.3325 & 1.3363 & 1.3359 & 1.3565 & 1.54 \\
\hline & $\mathrm{C} 13-\mathrm{C} 14$ & 1.4513 & 1.4455 & 1.4420 & 1.4438 & 1.4456 & 1.4611 & 1.07 \\
\hline & C14-C15 & 1.4923 & 1.5146 & 1.4890 & 1.4980 & 1.4985 & 1.5081 & 0.64 \\
\hline & $\mathrm{C} 15-\mathrm{C} 16$ & 1.5209 & 1.5207 & 1.5234 & 1.5238 & 1.5222 & 1.5261 & 0.27 \\
\hline & $\mathrm{C} 1-\mathrm{C} 16$ & 1.5422 & 1.5442 & 1.5475 & 1.5463 & 1.5451 & 1.5264 & -1.21 \\
\hline \multirow{10}{*}{$\begin{array}{l}\text { Angles } \\
\left({ }^{\circ}\right)\end{array}$} & C2-C1-O1 & 105.31 & 104.75 & 104.99 & 105.22 & 105.07 & 107.73 & 2.53 \\
\hline & $\mathrm{C} 1-\mathrm{C} 2-\mathrm{C} 8$ & 104.98 & 105.31 & 105.12 & 105.12 & 105.13 & 100.72 & -4.19 \\
\hline & $\mathrm{C} 2-\mathrm{C} 8-\mathrm{C} 7$ & 106.97 & 106.81 & 107.06 & 107.02 & 106.97 & 109.46 & 2.33 \\
\hline & C8-C7-O1 & 114.90 & 114.60 & 114.44 & 114.62 & 114.64 & 113.53 & -0.97 \\
\hline & C12-C1-C16 & 109.70 & 109.84 & 109.66 & 110.02 & 109.81 & 109.22 & -0.54 \\
\hline & $\mathrm{C} 1-\mathrm{C} 12-\mathrm{C} 13$ & 119.74 & 119.84 & 120.40 & 119.83 & 119.95 & 122.04 & 1.74 \\
\hline & C12-13-C14 & 122.39 & 122.51 & 121.79 & 122.53 & 122.31 & 122.20 & -0.09 \\
\hline & C13-C14-C15 & 118.33 & 118.29 & 119.26 & 118.33 & 118.55 & 116.79 & -1.48 \\
\hline & C14-C15-C16 & 115.22 & 114.68 & 114.97 & 115.43 & 115.08 & 117.83 & 2.39 \\
\hline & C1-C16-C15 & 109.34 & 109.16 & 109.00 & 108.72 & 109.06 & 111.62 & 2.35 \\
\hline
\end{tabular}

crystal diffraction data into one dimensional powder diffraction data. However, the transmission mode and synchrotron powder diffraction could be adopted to improve the resolution of the powder diffraction data, which will further improve the accuracy of the structure determination from powder diffraction data.

\section{Conclusions}

Based on our analysis, comparative crystal structure deter- mination of griseofulvin, single-crystal X-ray diffraction has validated the accuracy of powder X-ray diffraction. It can be demonstrated that developments in laboratory powder X-ray diffraction as well as computational methods and $\mathrm{X}$-ray resources over recent years have greatly promoted the development of powder X-ray diffraction. As a result, powder X-ray diffraction can be a powerful auxiliary implement to single-crystal X-ray diffraction in structure elucidating. Furthermore, the application of powder X-ray diffraction can be popularized in the field of structural elucidating of small organic molecules. 
1 Harris K D M, Tremayne M, Kariuki B M. Contemporary advances in the use of powder X-Ray diffraction for structure determination. Angew Chem Int Ed, 2001, 40: 1626-1651

2 David W I F, Shankland K, McCusker L B, et al. Structure Determination from Powder Diffraction Data. Oxford: Oxford University Press, 2006

3 Harris K D M, Cheung E Y. How to determine structures when single crystals cannot be grown: Opportunities for structure determination of molecular materials using powder diffraction data. Chem Soc Rev, 2004, 33: 526-538

4 Evans J S O, Evans I R. Beyond classical applications of powder diffraction. Chem Soc Rev, 2004, 33: 539-547

5 Tremayne M J. The impact of powder diffraction on the structural characterization of organic crystalline materials. Phil Trans R Soc Lond A, 2004, 362: 2691-2707

6 Lei X R, Yang J H, Lin X, et al. Crystal structure determination of Jatrorrhinzine chloride. Chin Sci Bull, 2009, 54: 3244-3248

$7 \mathrm{Hu} \mathrm{G} \mathrm{Q}, \mathrm{Li} \mathrm{H}$, Wang X J, et al. Measurement and correlation of griseofulvin solubility in different solvents at temperature from (281.95 to 357.60) K. J Chem Eng Data, 2010, 55: 3969-3971

8 Puttaraja, Nirmala K A, Sakegowda D S. Crystal structure of griseofulvin. J Crystallogr Spectrom Res, 1982, 12: 415-423
9 Malmros G, Wagner A, Maron L. (2S,6'R)-7-chloro-2',4,6,-trimethoxy-6'-methyl-spiro-(benzofuran-2(3H),2-(2')cyclohexene)-3,4'-dione $\mathrm{C}_{17} \mathrm{H}_{17} \mathrm{ClO}_{6}$. Cryst Struct Commun, 1977, 6: 463-470

10 Hu E P, Cheng Q, Guo L H, et al. Crystal structure determination of 7-ADCA based on X-ray powder diffraction. Chin Sci Bull, 2006, 51: 2421-2424

11 Guo P, Su Y H, Cheng Q, et al. Crystal structure determination of the $\beta$-cyclodextrin- $p$-aminobenzoic acid inclusion complex from powder X-ray diffraction data. Carbohydrate Res, 2011, 346: 986-990

12 Ma L D. Neoteric X-Ray Polycrystalline Diffraction. Beijing: Chemical Industry Press, 2004

13 Dolomanov O V, Bourhis L J, Gildea R J, et al. OLEX2: A complete structure solution, refinement and analysis program. J Appl Cryst, 2009, 42: 339-341

14 Neumann M A. X-cell: A novel indexing algorithm for routine tasks and difficult cases. J Appl Crystallogr, 2003, 36: 356-365

15 Sheldrick M G. SHELXS-97: Program for Crystal Structure Solution. Gotingen: University of Gotingen, 1997

16 Sheldrick M G. SHELXL-97: Program for Crystal Structure Refinement. Gotingen: University of Gotingen, 1997

17 Wei R B, Liu Y, Liang Y. Researching progress of pesticides containing spiral structure. Chin J Org Chem, 2009, 3: 476-487

Open Access This article is distributed under the terms of the Creative Commons Attribution License which permits any use, distribution, and reproduction in any medium, provided the original author(s) and source are credited. 